\title{
1 \\ MODELING POSTERIOR CERVICAL FORAMINOTOMY AND DISCECTOMY APPROACH IN SHEEP CADAVER CERVICAL SPINE
}

\author{
(D) Tuncer Tașcıoğlu' , (D) Bekir Mahmut Kılınç²
}

\author{
${ }^{1}$ Ankara Training and Research Hospital, Clinic of Neurosurgery, Ankara, Turkey \\ ${ }^{2}$ University of Health Sciences Turkey, Haseki Training and Research Hospital, Clinic of Neurosurgery, İstanbul, Turkey
}

\begin{abstract}
Objective: The aim of this study was to assess whether a sheep cadaver cervical spine model could be useful in modeling all steps and stages of the posterior cervical foraminotomy and discectomy surgery, which was frequently used in daily practice, and to assess its suitability for laboratory training.

Materials and Methods: A whole sheep neck which had not undergone muscle stripping was obtained from a butcher and was used to model the posterior cervical foraminotomy and discectomy surgery by assessing the following steps performed under microscopy: 1-Stripping of the paravertebral muscles, 2- Determination of the borders of cervical laminae, 3- Recognition of cervical facets, 4- Performing laminectomy, 5Determination and removal of the ligamentum flavum, 6- Defining the cervical duramater, 7- Performing cervical foraminotomy and exposure of the cervical nerve root, and 8- Determination of disc distance.

Results: The posterior cervical foraminotomy and discectomy model in sheep cadaver cervical spine was able to simulate the osseous, ligamentous, and neural stages of the surgical approach at a similar level to the human spine.

Conclusion: We believe that the proposed posterior cervical foraminotomy and discectomy model can effectively simulate all steps of this surgery, thus contributing to the anatomical orientation during surgical intervention, and such studies will most likely have a positive effect on surgical interventions in general due to their contribution to the ability to recognize and use relevant instruments.

Keywords: Training modeling, posterior cervical approach, sheep cadaver, cervical spine
\end{abstract}

\section{INTRODUCTION}

Surgical education generally has a process that can be described as "see one, do one and teach one". However, the recent increases in malpractice cases and greater involvement of patients' relatives in treatment necessitates changes in this classical surgical training process, and therefore, increases the importance of experimental studies before encountering the same procedures in patients. Cadavers, living animals, placentas and synthetic products (plastic, latex and silicone) have been used in laboratory studies so $\mathrm{far}^{(1)}$. Among these, animal cadaver models differ from other models in that they do not pose any ethical problems, are more accessible, have lower costs, and have anatomical and tissue similarities.

Animal cadaver studies have been evaluated in different studies to model both cranial and spinal interventions ${ }^{(2,3)}$. In the study by Kandziora et al. ${ }^{(4)}$, comparing sheep and human cervical spines, it was stated that sheep cervical spine can be used for human spine studies even though there are significant differences between the two structures. To our knowledge, studies concerning the intraspinal region of the cervical spine of sheep are very limited ${ }^{(2,5)}$.

In this study, we aimed to perform the posterior cervical foraminotomy and discectomy surgery, which is a frequently used surgery in daily practice, in sheep cadaver spines to evaluate the similarities of the application steps to procedures applied on the human spine.

\section{MATERIALS AND METHODS}

The neck of a sheep over 2 years old with non-stripped muscles was obtained from a local butcher as a whole (Figure 1). A Carl-Zeiss Opmi 1 operating microscope was used throughout all surgical steps. The surgical steps to be evaluated in the cadaver model were determined as follows: 1- Stripping of the paravertebral muscles, 2- Determination of the borders of cervical laminae, 3-Recognition of cervical facets, 4-Performing keyhole laminectomy, 5- Determination, and removal of the ligamentum flavum, 6- Defining the cervical dura, 7- Performing cervical foraminotomy and exposure of the cervical nerve root, 8- Determination of disc distance. 
turkishspine

Ankara Training and Research Hospital has decided that the ethics committee approval of Animal Cadaver Study number 845 is not required according to "Regulation on Working Procedures and Principles of Animal Experiments Ethics Committees Article 8 19-k" (date 22/12/2021).

\section{RESULTS}

The sheep was placed on the table with the posterior surface of the neck on the upside. Spinous processes were palpated, and paravertebral muscles were stripped over two

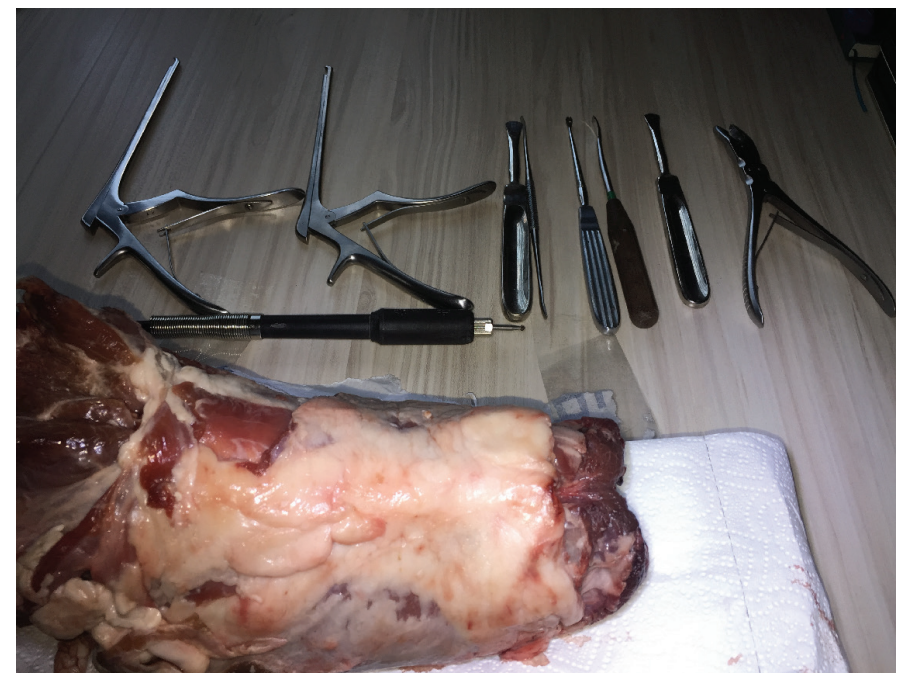

Figure 1. The neck of a sheep over 2 years old with non-stripped muscles

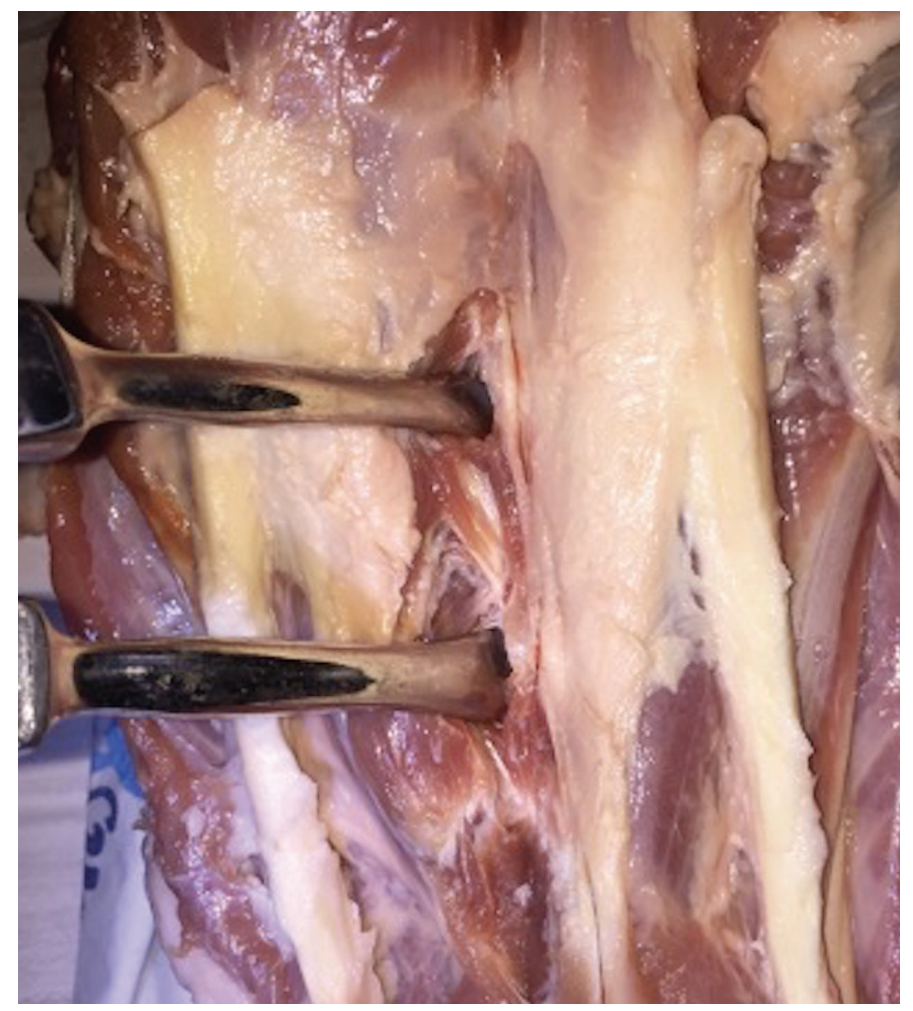

Figure 2. Stripping of the paravertebral muscles consecutive spinous processes (Figure 2). Then, the borders of two consecutive laminae and facet joint were determined, followed by determination of the ligamentum flavum (Figure 3), and a keyhole-shaped laminectomy was performed (Figure
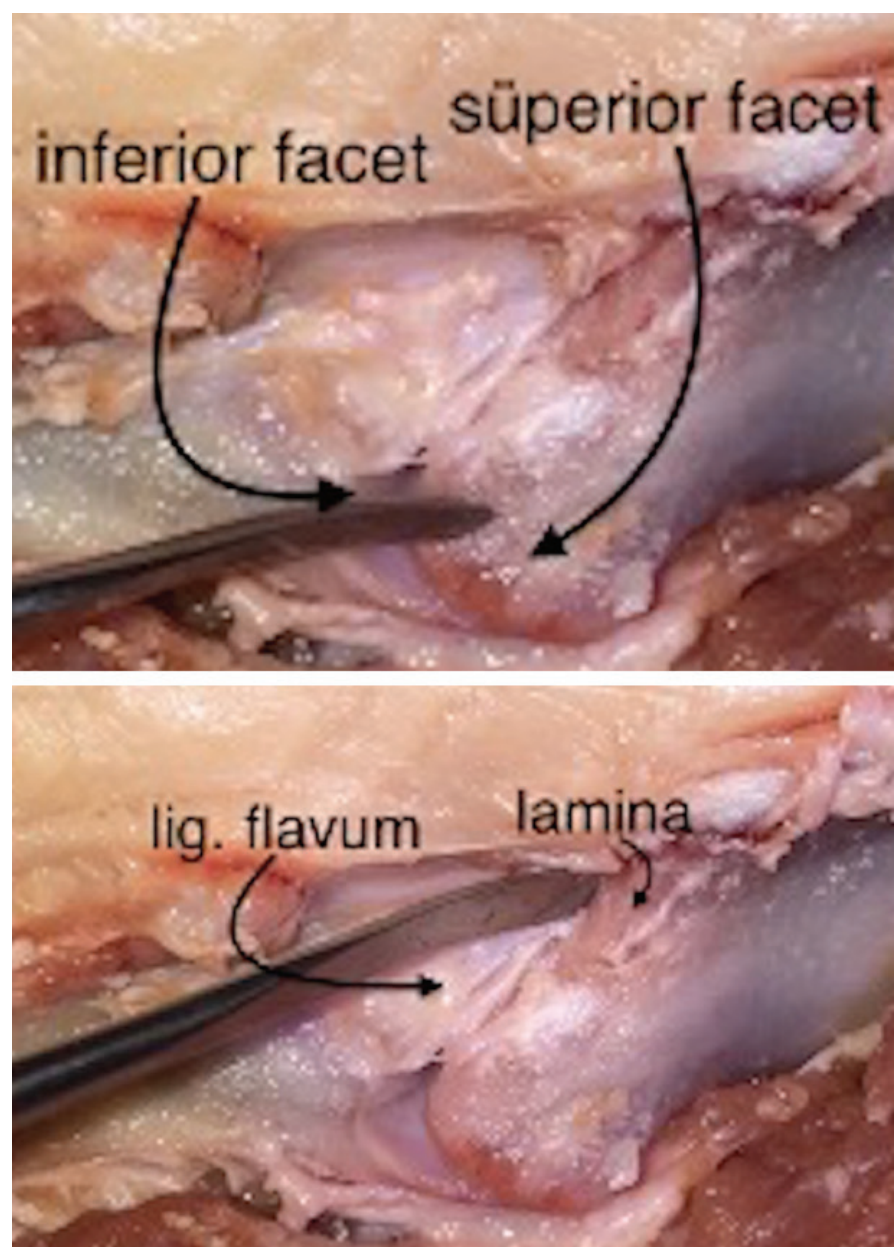

Figure 3. The borders of two consecutive laminae and facet joint were determined

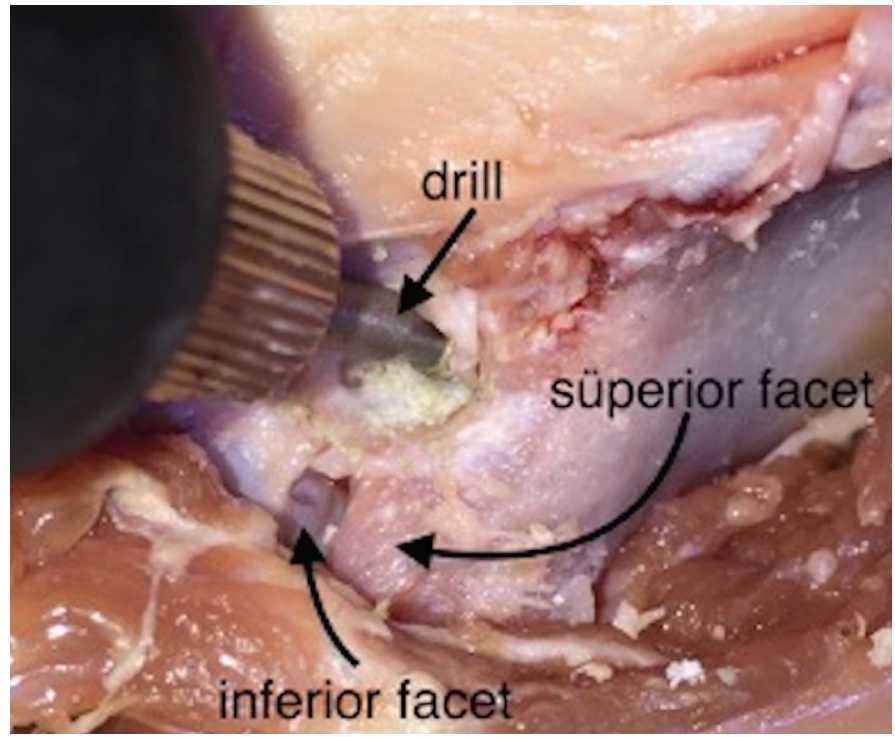

Figure 4. Keyhole-shaped laminectomy was performed 


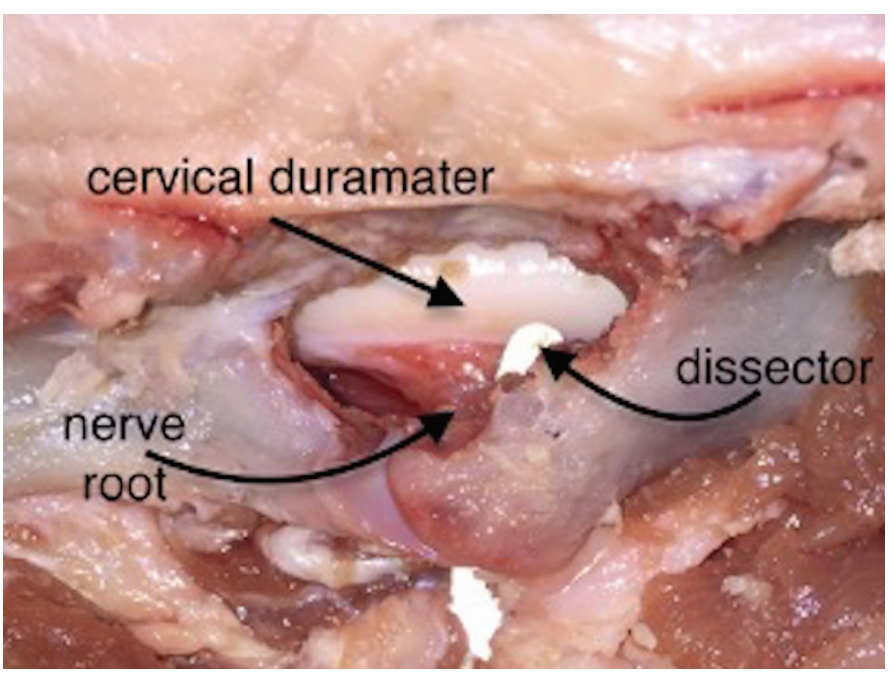

Figure 5. The cervical duramater, nerve root and cervical foramen

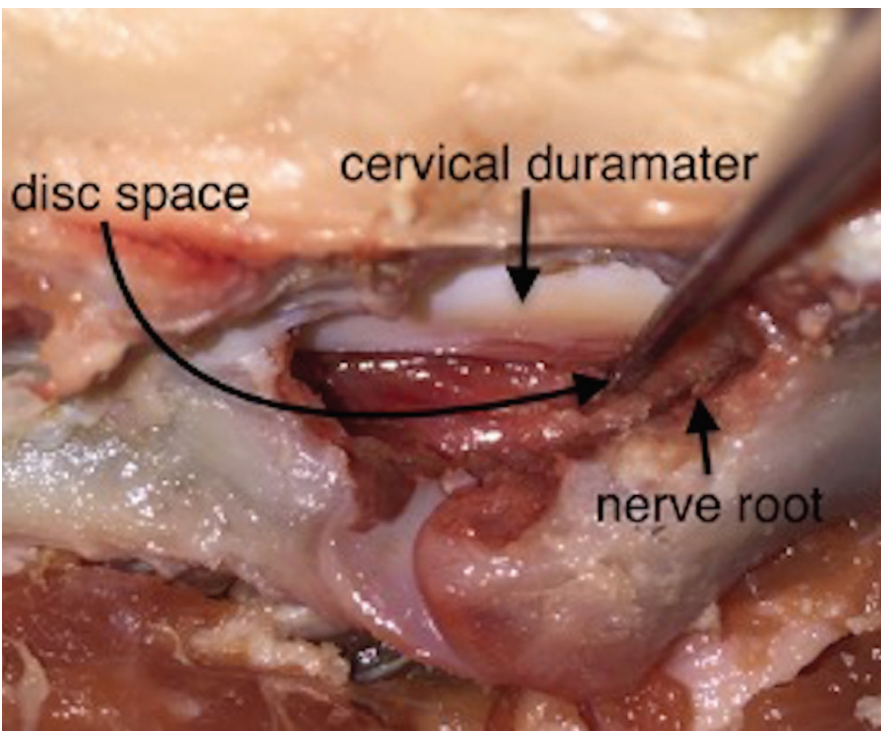

Figure 6. Determination of disc distance

4) After the cervical dura was defined, the cervical nerve root was identified by performing cervical foraminotomy (Figure 5). Lastly, discectomy was performed by determining the disc distance (Figure 6).

\section{DISCUSSION}

Traditional surgical education is based on the masterapprentice relationship, but this situation has been questioned for a long time and it is emphasized that this education model should be supported by laboratory and experimental training(6). Therefore, important studies aiming to standardize presurgical laboratory training have been performed ${ }^{(7,8)}$. In these studies, mostly models were used. Although the anatomical simulation ability of these models, which can be used unlimitedly, is high, the ability to simulate tissue is almost non-existent. The cost of human cadaver studies and the need for special areas for storage limit their accessibility and they still do not have the ability to simulate in vivo situations, similar to model studies. Considering this situation, living animal models seem to be ideal for laboratory studies due to their anatomical similarity and viability, but recently increasing ethical concerns also limit the use of these models. Although the lack of viability of animal cadaver models is an important shortcoming, they have important advantages such as accessibility, anatomical and simulation ability, low cost, and the fact that special storage areas are not necessary ${ }^{(9-11)}$.

We conducted our study using sheep cadaver spine to model posterior cervical foraminotomy and discectomy surgery used in the treatment of cervical disc herniation, which is frequently encountered in daily practice. Posterior cervical foraminotomy and discectomy is a minimally invasive surgical procedure that can be performed with a microscope or via endoscopy in selected cases of cervical disc herniation. In posterior cervical foraminotomy and discectomy, complications such as dysphagia, hematoma, and laryngeal nerve damage which may be encountered in anterior surgery, are not observed. Also, since fusion is not performed, adjacent segment degeneration is not expected, but complications such as neck pain, muscle spasm and greater blood loss may occur $^{(12)}$.

Of note, a simulator was developed for this specific intervention by the Congress of Neurological Surgeons Simulation Committee for use in neurosurgery training. The effectiveness of this simulator, created with a 3D printer, was evaluated by Harrop et al. ${ }^{(13)}$ in terms of level detection, use of drills, removal of the laminae, decompression of neural structures and preservation of tissues, and it was stated that it could be useful for education.

Taking this information into account, the sheep cadaver cervical spine model we developed lacks the ability to simulate bleeding (similar to the spinal simulator); therefore, it is also insufficient in providing management skills concerning bleeding, which is a perioperative problem in posterior cervical foraminotomy and discectomy surgery. However, the sheep cervical spine cadaver model has some advantages. It can simulate all the targeted and tested stages in this simulator in line with bone anatomy, as well as providing the potential to practice paravertebral muscle stripping and increase experience in the recognition and removal of the ligamentum flavum and recognition of the dura mater and nerve roots.

\section{CONCLUSION}

We believe that the present posterior cervical foraminotomy and discectomy model in sheep cervical spine can effectively simulate all steps of this surgery, thus contributing to anatomical orientation during surgical intervention. In addition, the utilization of these studies will have a positive effect on 
similar surgical interventions due to its contribution to the ability to recognize and use relevant surgical instruments.

\section{Ethics}

Ethics Committee Approval: Ankara Training and Research Hospital has decided that the ethics committee approval of Animal Cadaver Study number 845 is not required according to "Regulation on Working Procedures and Principles of Animal Experiments Ethics Committees Article 8 19-k" (date 22/12/2021).

Informed Consent: Animal cadaver study.

Peer-review: Externally and internally peer-reviewed.

\section{Authorship Contributions}

Surgical and Medical Practices: T.T., B.M.K., Concept: T.T., B.M.K., Design: T.T., Data Collection or Processing: B.M.K., Analysis or Interpretation:T.T., B.M.K., Literature Search:T.T., B.M.K., Writing: T.T., B.M.K.

Financial Disclosure: The authors declared that this study received no financial support.

Conflict of Interest: The authors have no conflicts of interest to declare.

\section{REFERENCES}

1. Olijnyk LD, Patel K, Brandão MR, de Morais ANL, de Carvalho RF, Severino AG, et al. The role of low-cost microsurgical training models and experience with exercises based on a bovine heart. World Neurosurg. 2019;130:59-64.

2. Morosanu CO, Nicolae L, Moldovan R, Farcasanu AS, Filip GA, Florian IS. Neurosurgical cadaveric and in vivo large animal training models for cranial and spinal approaches and techniques - A systematic review of the current literature. Neurol Neurochir Pol. 2019;53:8-17.

3. Al-Sharshahi ZF, Hoz SS, Alrawi MA, Sabah MA, Albanaa SA, MoscoteSalazar LR. The use of non-living animals as simulation models for cranial neurosurgical procedures: A literature review. Chin Neurosurg J. 2020;6:1-5.

4. Kandziora F, Pflugmacher R, Scholz M, Schnake K, Lucke M, Schröder $\mathrm{R}$, et al. Comparison between sheep and human cervical spines: An anatomic, radiographic, bone mineral density, and biomechanical study. Spine. 2001;26:1028-37.

5. Gragnaniello C, Abou-Hamden A, Mortini P, Colombo EV, Bailo M, Seex KA, et al. Complex spine pathology simulator: an innovative tool for advanced spine surgery training. J Neurol Surg A Cent Eur Neurosurg. 2016;77:515-22.

6. Aboud E, Al-Mefty O, Yaşargil MG. New laboratory model for neurosurgical training that simulates live surgery. J Neurosurg. 2002;97:1367-72.

7. Patel EA, Aydin A, Cearns M, Dasgupta P, Ahmed K. A systematic review of simulation-based training in neurosurgery, part 2: spinal and pediatric surgery, neurointerventional radiology, and nontechnical skills. World Neurosurg. 2020;133:e874-92.

8. Patel EA, Aydin A, Cearns M, Dasgupta P, Ahmed K. A systematic review of simulation-based training in neurosurgery, part 1: cranial neurosurgery. World Neurosurg. 2020;133:e850-73.

9. Hamamcioglu MK, Hicdonmez T, Tiryaki M, Cobanoglu S. A laboratory training model in fresh cadaveric sheep brain for microneurosurgical dissection of cranial nerves in posterior fossa. $\mathrm{Br} J$ Neurosurg. 2008;22:769-71.

10. Hicdonmez T, Hamamcioglu MK, Tiryaki M, Cukur Z, Cobanoglu S. Microneurosurgical training model in fresh cadaveric cow brain: a laboratory study simulating the approach to the circle of Willis. Surg Neurol. 2006;66:100-4.

11. Suslu HT, Tatarli N, Karaaslan A, Demirel N. A practical laboratory study simulating the lumbar microdiscectomy: Training model in fresh cadaveric sheep spine. J Neurol Surg A Cent Eur Neurosurg. 2014;75:167-9.

12. Badiee RK, Mayer R, Pennicooke B, Chou D, Mummaneni P V, Tan LA. Complications following posterior cervical decompression and fusion: A review of incidence, risk factors, and prevention strategies. J Spine Surg. 2020;6:323-33.

13. Harrop J, Rezai AR, Hoh DJ, Ghobrial GM, Sharan A. Neurosurgical training with a novel cervical spine simulator: Posterior foraminotomy and laminectomy. Neurosurgery. 2013;73 Suppl 1:94-9. 